\title{
La atención como fenómeno de apertura cognoscitiva al mundo. Una aproximación fenomenólogica
}

\author{
Attention as a phenomenon \\ of cognoscitive opening to the world. \\ A phenomenological approach
}

JORGE MONTESÓ VENTURA

Centre d'estudis antropològics ACAF, Valencia (España)

Recibido: 26/06/16 Aceptado: 10/08/16

\section{RESUMEN}

La atención es un fenómeno cognitivo que, debido a sus múltiples funciones y a su permeabilidad a aspectos emocionales y culturales, resulta un fenómeno de difícil definición. Al tiempo, eso que por una parte dificulta su aprehensión, por otra la convierte en una pieza fundamental para comprender el comportamiento humano, particularmente el modo en que interactúa con su medio. En el presente artículo queremos revisar el papel de la atención en los procesos de toma de conciencia que permiten al sujeto una adecuada adaptación al medio y cómo, a través de ella, configurar su perspectiva de la realidad, su «mundo».

PALABRAS CLAVE:

ATENCIÓN, PERCEPCIÓN, REALIDAD, MUNDO, FENOMENOLOGÍA.

\begin{abstract}
Attention is a cognitive phenomenon that, for its multiple functions and its permeability to emotional and cultural aspects, it's a phenomenon with difficult definition. At the same time, the reasons that difficult its definition makes it a fundamental piece to understand the human
\end{abstract}


behaviour, particularly the way that it interacts with its environment. In this article, we want to review the role of attention in the awareness process that allow the subject an adequate adaptation to the environment, and, through it, set his perspective of reality, his own «world».

KEYWORDS:

ATTENTION, PERCEPTION, REALITY, WORLD, PHENOMENOLOGY.

\section{NUESTRA SALIDA AL MUNDO, INTRODUCCIÓN}

CUANDO HABLAMOS DE NUESTRA SALIDA COGNOSCITIVA AL MUNDO nos referimos al modo en que el ser humano toma consciencia de su medio entorno, de su circunstancia, esto es, de ese horizonte en el que se halla y que no solo contempla, sino que vive. La realidad en la que nos situamos, la que nos circunda y conforma el substrato de lo que será nuestro «mundo», llega a nosotros a través de nuestro cuerpo -coordenada cero que dispensa toda perspectiva- en forma de imputs o estímulos sensibles que nuestros sentidos captan y ofrecen al cerebro para su interpretación, pues, como ya dijese el estagirita, «nada hay en la mente que no haya estado antes en los sentidos». Ahora bien, aunque fisiológicamente lo que recojamos sean meras impresiones sensitivas, no interactuamos con un caos de sensaciones aisladas, hasta el acontecimiento más elemental está ya revestido de cierto sentido. ${ }^{1}$ Nuestra percepción (percaptare ${ }^{2}$ ) se da no solo a través de los órganos sensitivos, sino que en dicho proceso intervienen elementos y procesos superiores como el uso de conceptos -el lenguaje en su generalidad ${ }^{3}-$, la memoria -nuestra historia de vida-, emociones, elementos que dotan a la captación sensitiva, a nuestros accesos al mundo, de un determinado sentido (logos), de una organización en la percepción que, más allá de relacionarnos con sensaciones, nos llevan a percibir cosas. Ello sucede porque nuestra salida al mundo no se produce como si fuésemos seres atemporales, vacuos o vanos; nuestra salida al mundo es la apertura de un «yo» histórico, repleto de preferencias e intereses, motivado por la consumación de un determinado objetivo, con un proyecto de vida, con una intencionalidad. Nuestra salida al mundo no se

1 Ver en MERLEAU- PONTY, M. (1985). Fenomenología de la percepción. Barcelona: Planeta, p. 31.

2 Percibir, percaptare, alude no solo a la visión de las cosas, sino también a la captación del sentido de las mismas, al modo de ver, a la percepción de la naturaleza interna de la cosa. De aquí que Ortega reparase en que «si devolvemos a la palabra percepción su valor etimológico -donde se alude a coger, apresar- el concepto será el verdadero instrumento u órgano de la percepción y apresamiento de las cosas» (OC, I, 784).

3 Ver en VYGOTSKI, L. S. y LURIA, A. R. (2007). El instrumento y el signo en el desarrollo del niño. Madrid: Fundación Infancia y aprendizaje, p. 38. 
da, así, mediante la visión, el oído o el tacto, sino a través del gesto de mirar, de escuchar, de tocar; nuestra salida al mundo se da a través de un acto intencional que implica la concentración de nuestra vida de conciencia, esto es, mediante la focalización de nuestra atención.

Por ello, por el hecho de no limitarnos a ver sino a mirar, en nuestra salida -salvo en situaciones mórbidas- nunca interactuamos con un haz de luces o un caos de sensaciones, sino con estructuras de significación (v. g. objetos), con sistemas definidos a través de una red de conexiones y disyunciones, de limites, que ligan cada cosa con el todo y este con nosotros. Esa red de sensaciones que conforman estructuras significativas la esbozamos, fundamentalmente, a través de la mediación del lenguaje, de la intromisión en la percepción de un conjunto de predicados culturales ${ }^{4}$ que, a través del patrimonio conceptual adquirido por el hecho de nacer en una comunidad cultural, determinan nuestra visión del mundo (Weltanschauung). Así, nuestro Lebenswelt, inevitablemente, es un mundo de la vida cultural, pues nacemos y vivimos en cultura y a través de ella nos pronunciamos.

Por tanto, nuestra salida al mundo se da, efectivamente, a través de un proceso de percepción mediante el cual nuestro ser se abre cognoscitivamente al mundo, una percepción que va más allá de la mera captación de impresiones, pues pretende la comprensión del significado de lo visto, un significado que se obtiene al des-cubrir (alétheia) la naturaleza interna de las cosas, su intimidad, porque «la percepción consta, como toda vivencia, de elementos reales (reel) noéticos, y de correlatos intencionales, o «contenido noemático» [...]. La percepción, como toda vivencia, tiene un sentido». ${ }^{5}$

\section{LA ATENCIÓN DESDE EL CONTAR-CON AL REPARAR-EN ${ }^{6}$}

Siendo que nuestra interacción con la realidad, nuestro conocimiento del mundo, no se da únicamente mediante la captación pasiva de impresiones -de lo patente-, sino que requiere del gesto activo del ser humano, de la tendencia centrífuga de su intimidad para captar el sentido -lo latente ${ }^{7}$ de lo visto,

4 Sobre la importancia de los predicados culturales en la percepción ver: MONTESÓ, J. (2016). Ortega y los predicados culturales de la percepción. Ágora: papeles de filosofía, 35 (2), pp. 157-175.

5 SAN MARTÍN, J. (2008). La percepción como interpretación. Investigaciones fenomenológicas, 6, p. 20.

6 Sobre las diferencias entre reparar en y contar con es muy interesante leer ORTEGA Y GASSET, J. (2008). Principios de metafísica según la razón vital. Curso de 1932-1933. Obras Completas, VIII. Madrid: Taurus.

7 Hemos visto cómo lo percibido, para serlo de un modo pleno, precisa del concepto -de alcanzar el sentido de las cosas- como elemento complementario a la impresión, siendo ambas dos dimensiones fundamentales de nuestra percepción de la realidad. Ello evidencia la dualidad que 
evidenciamos que la atención, fenómeno responsable de semejante gesto de tender-hacia (ad-tendere), resultará fundamental. Veamos, pues, el papel que esta desempeña en semejante proceso de apertura y toma de conciencia.

Estudios como los de Heidegger nos han mostrado cómo el modo más primario de ser del ser humano es el de estar arrojado al mundo en torno, existiendo o, dicho en palabras de Ortega, viviendo ejecutivamente su vida a través de su tendencia a lo otro, al conjunto de alteridades de las que interesa en cuanto ocupaciones, en cuanto asuntos que le atañen. Decía el madrileño que «vivir es existir fuera de sí, estar fuera, arrojado de sí, consignado a lo otro». ${ }^{8}$ Podemos afirmar que la disposición primera y primaria del ser humano es aquella en la que este se halla ocupado en sus quehaceres, absorto en sus ocupaciones. Heidegger ${ }^{9}$ llama a este modo de estar en el mundo besorgen. Dice el germano que nuestra ocupación con las cosas, con las que conforman nuestros asuntos, se da siempre bajo una actitud cuidadosa (Sorge), bien podríamos decir, atenta..$^{10}$ Las cosas nos ocupan en tanto son presa de nuestro interés, en tanto despiertan en nosotros el propósito de su uso bajo un fin determinado, lo que requiere de nuestro cuidado, de nuestra atención, pues atender a algo implica verter sobre ello toda nuestra vida de conciencia, nuestra plena dedicación, es ocuparnos con ese algo desde cierta preocupación necesaria para que la interacción resulte óptima, según nuestras expectativas. «El cuidado, en cuanto totalidad estructural originaria, se da existencialmente a priori «antes», es decir, desde siempre, en todo fáctico «comportamiento» $\mathrm{y}$ «situación» del Dasein». ${ }^{11}$ Cuidado es anticiparse-a-sí-estando-ya-en-un-mundo. ${ }^{12}$ Por ello decimos que cuando salimos al mundo lo hacemos desde la pre-ocupación, empujados por la motivación que despierta nuestro interés hacia las cosas, esto es, emergemos desde una pre-visión o planificación que pretende ejecutar nuestra tarea del modo más adecuado a un fin determinado. Así, para Heidegger, el modo primario de

la fenomenología -siendo esta una de las más importantes aportaciones orteguianas a la misma (San Martín 2012, 179)- describe en el análisis de la realidad en tanto vivida, dos dimensiones que ofrecen, de un modo sintético, la integridad de lo percibido: la faz ejecutiva -patente- y la virtual -latente-.

8 OC, VIII, 590-591. Principios de metafísica según la razón vital. 1932-1933.

9 HEIDEGGER, M. (2009). Ser y tiempo. Madrid: Ed. Trotta. (\$57).

10 Es pertinente observar cómo incluso la voz popular usa a la par expresiones como «ten cuidado» o «presta atención», «sé cuidadoso» o « sé atento». «Cuidado» y «atención» son conceptos extremadamente vinculados, pues tener cuidado de algo supone convertir ese algo en foco de atención, convertirlo en figura y dedicarle a él los mejores tratos, la mayor eficacia en la acción. Ser cuidadoso o ser atento implica pues, no solo la puesta en marcha de las mejores facultades, sino una planificación previa de la acción, una pre-ocupación que, como veremos, es fundamental para explicar toda acción humana.

11 HEIDEGGER, M. op. cit., p. 211.

12 Ibíd., p. 210. (\$41). 
estar-en-el-mundo es el de estar ocupados para con lo otro, naufragando en nuestros asuntos como diría Ortega, interactuando con las cosas en tanto nos servimos de ellas. Pero lo principal, entonces, no son las cosas, sino la interacción que tenemos con ellas, el modo en que nos abrimos a ellas, esto es, la atención no está entonces orientada a la cosa-en-sí sino fundamentalmente a la tarea, por lo que, en lo que respecta a las cosas, simplemente necesitamos contar con ellas. De este modo, mientras la ejecución fluya libre de resistencias, el sujeto no necesitará de ningún proceso reflexivo o alteración atencional, no necesitará reparar en las cosas de las que se está sirviendo, para su fin, simplemente las utilizará, las vivirá. El sujeto ejecutivo desempeña su tarea en un estado que podríamos definir como pre-reflexivo o pre-teorético por el que vive vertido en sus asuntos, agarrado a ellos con la atención, de ahí que Ortega afirme que «lo que las cosas son primariamente es lo que son cuando no pensamos en ellas, antes de que pensemos en ellas, lo que son cuando contamos con ellas, cuando simplemente las vivimos».13

Ahora bien, puede suceder que, en un determinado momento, me habitúe a la tarea y libere parte de mi atención (v. g. automatismos) pudiendo, entonces, cambiar el foco de la misma para ir a las cosas -o a mí mismo- mientras sigo ejecutando; o puede suceder que en un determinado momento algo resista mi tendencia-a mis asuntos y ponga en riesgo el desarrollo de la tarea. En este caso, los enseres de los que me estoy valiendo, esos que utilizo en mi ejercicio, dejarán de presentarse como tales convirtiéndose de facilitadores apenas atendidos (con los que solo contábamos) en resistencia que obliga el concentrado de toda mi atención sobre ellos, pues deberé analizar qué está sucediendo para retomar asî mi actividad. Con la interrupción, pues, rompo la tendencia a la tarea y libero mi atención de ella para reparar en los posibles elementos resistentes que debo des-cubrir para ocuparme de ellos.

Al liberar nuestra atención de la tarea, esta emprende otra muy distinta, pues «nosotros nunca permanecemos en suspenso en nada». ${ }^{14}$ Acontece que la tarea que urge ahora es la de esbozar un inquisidor recorrido por el campo perceptivo trazando un itinerario que inventaríe la pluralidad de potenciales enseres con los que me estaba desenvolviendo para, objetivándolos uno a uno, dar con el elemento en discordia, con el causante de la rotura de mi ejecutividad, y actuar en consecuencia. En ese percatarse o reparar en los elementos de resistencia convertimos los distintos facilitadores (enseres) en objetos, pues cuando paramos mientes en ellos lo que hacemos es fijarlos, acotarlos, definir sus límites, acentuarlos sobre el resto de elementos del entorno como figuras sobresalientes en el horizonte de percepción. Solo así conseguimos conocerlos, es así cómo

13 OC, VIII, 601. Principios de metafísica según la razón vital.

14 MERLEAU- PONTY, M. op.cit., p. 459. 
tomamos consciencia plena de ellos y, a su vez, de nuestra coexistencia con ellos, pues siempre son vistos desde nuestra particular perspectiva, con todos los matices culturales e históricos que ello implica. Así, la atención escrutará el horizonte ejerciendo sus labores de selección frente a lo que consideraremos ruido perceptivo, unificando estímulos en conjuntos perceptivos para reparar en las distintas estructuras de significación que reconozca, filtrado la información necesaria para alcanzar nuestro objetivo. ${ }^{15}$

Con todo, para conocer la circunstancia, como sucede en el desempeño de toda actividad, debo pues, como poco, atenderla. Pues, como diría Ortega, «se olvida demasiado la humilde perogrullada de que para ver hay que mirar, y para mirar hay que fijarse, es decir hay que atender». ${ }^{16}$ Sin un mínimo de atención no se dará el acceso ejecutivo del yo a la circunstancia, pero tampoco se producirán los necesarios procesos selectivos, de ordenación de planos, jerarquización de impresiones, filtrajes y fijaciones que necesito para tomar consciencia de los objetos con los que estoy naufragando. Y es importante el último matiz: hablamos de objetos con los que ya estoy naufragando, objetos con los que, de un modo apenas atento, estoy y estaba ya interactuando. Sucede que, cuando reparo en ellos, me doy cuenta de que ya estaban ahí antes de ser atendidos por mí, pues ya contaba con ellos, ya estaban dispuestos antes de que reparásemos en ellos. Hasta que no se han vuelto objeto de mi cuestionamiento no los he atendido debidamente. Ser cuestión significa que buscamos su ser, y esto, a su vez, implica que ya teníamos cierta relación previa con ese algo -pues lo buscamos-. El reparar-en no es más que un efecto de revelación o des-cubrimiento que se da cuando reconozco con cierta plenitud ciertos objetos en el entorno, una especie de iluminación por reconocimiento. Dicho de otro modo, el reparar-en sucede cuando, guiados por una determinada idea o concepto previo, salimos al mundo escrutando el horizonte con la intención de agrupar o delimitar las impresiones que en él se nos dan según determinadas estructuras de significado previas, tornando así el conjunto de impresiones en figuras, en estructuras significativas que emergen -tras la idea- en forma de objetos. Cuando la idea correlaciona con un conjunto de impresiones, se produce ese efecto de iluminación, o lo que Schapp definía como claridad mental (Deutlichkeit ${ }^{17}$ ), que se da cuando descubrimos en el horizonte de percepción determinados elementos

15 Sobre las tareas que desempeña la atención en la cognición humana podemos seguir el epítome de Luck y Vecera (2012): a) orientación y eficiencia frente a la tarea; b) procesos selectivos frente al ruido perceptivo; c) filtrado en el procesamiento de la información para evitar cuellos de botella; d) unificación de estímulos en conjuntos perceptivos; e) ganancia o debilidad en los procesos de memoria; f) acceso preferencial frente a tareas.

16 OC, III, 895. Ideas sobre la novela.

17 Ver en SCHAPP, W. (1910). Beiträge zur Phänomenologie der Wahrnehmung. Gotinga: M. Niemeyer, Halle/S. 
sensibles (color, luz, forma) que responden, como correlatos objetivos, a nuestra idea previa, dirimiéndolos así en objetos. Decía Ortega que:

para ver, en suma, es preciso fijarse. Pero fijarse es buscar el objeto de antemano y es como un preverlo antes de verlo. A lo que parece, la visión supone una previsión que no es obra ni de la pupila ni del objeto, sino de una facultad previa encargada de dirigir los ojos, de explorar con ellos el contorno: es la atención [...]. Pero la atención no es otra cosa que una preferencia anticipada, preexistente en nosotros, por ciertos objetos. ${ }^{18}$

Como decía Ortega, con la atención salimos al entorno para buscar aquello de lo que ya tenemos cierta relación previa, cierta pre-visión. Nunca percibiremos aquello de lo que no sepamos o no tengamos interés por encontrar. Atender es salir motivadamente al mundo tras una idea o un interés previo que intenta encontrar (descubrir) en él su correlato objetivo, de ahí que hablemos de previsión en Ortega y del efecto de claridad mental en Schapp.

Es, pues, con la atención que podemos emprender nuestra apertura al mundo, una salida motivada, intencional -como apuntarían Husserl y Brentano-, una fluencia desde nuestra situación hacia fuera, centrífugamente, escrutando el horizonte en y desde nuestra perspectiva vital, buscando aquello que responda a nuestras preferencias, a nuestros intereses. Salimos al mundo mediante una mirada motivada por los intereses que en cada momento espolean nuestra voluntad, tras esa ley del interés ${ }^{19}$ donde este, el interés, aparece como el incentivo, temporalmente circunscrito, que mueve la atención humana como un foco luminoso que va revelando los distintos elementos de la realidad. Con esa atención interesada -valga la redundancia- es con la que alcanzo mi personal e intransferible perspectiva de la realidad, la que permite que esta sea verdadera para mí y alcance a conformar mi propio «paisaje», mi mundo. Decía Morón Arroyo que «la verdad cambia en consonancia con la atención que el hombre le dedica [...]. Comprobación de las diferentes estructuras que toma el mundo según la importancia que se dé a sus distintos elementos». ${ }^{20}$

18 OC, VI, 210. Corazón y cabeza.

19 El postulado de esta ley enlaza el pensamiento orteguiano con el scheleriano y su ordo amoris, explicando cómo ciertas emociones pueden motivar nuestra atención hacia las cosas. Ver en SCHELER, M. F. (2001). Ética: nuevo ensayo de fundamentación de un personalismo ético. Madrid: Caparrós. A su vez, sobre el papel que los distintos intereses ejercen en los diferentes tipos de conocimiento de la realidad ver: HABERMAS, J. (1982). Conocimiento e interés. Madrid: Taurus. Sobre una visión más orteguiana de tal relación: RODRÍGUEZ HUÉSCAR, A. (1985). Perspectiva y verdad. Madrid: Alianza.

20 MORÓN ARROYO, C. (1968). El sistema de Ortega y Gasset. Madrid: Alcalá, p. 124. 
Así, quizá la atención sea el elemento más vago y escurridizo del aparejo cognitivo humano, ${ }^{21}$ un fenómeno que, pese a que James profiriese aquello de que «todo el mundo sabe lo que es la atención», ${ }^{22}$ la historia y la investigación nos ha hecho tomar consciencia de que quizá nos ocurra como a San Agustín con el tiempo, que «cuando nadie me lo pregunta, lo sé; cuando quiero explicarlo, no lo sé»:23 quizá, como dijese Husserl, y esta aproximación nos puede valer para la ocasión, «la extensión del concepto unitario de atención [...] se dilata sobre una esfera que llega hasta donde llegue el concepto de conciencia de algo». ${ }^{24}$ Para nosotros, como desplegaremos a continuación, la atención será aquel fenómeno que, respondiendo a cierto rol de mayordomo en el complejo aparejo cognitivo, sin afán de protagonismo y asistiendo a muchas otras funciones, puede que sea el más fundamental e ineluctable para el ejercicio propiamente humano, pues el propio James lo indicaba, toda mi experiencia, todo lo que hace que yo sea quien soy, es justo aquello a lo que decido prestar atención. ${ }^{25}$

\section{EL MODELO DEL MAYORDOMO O EL LUGAR DE LA ATENCIÓN EN LA TÓPICA INTERIOR}

La mejor manera de definir un fenómeno como el de la atención es través de sus funciones. En el presente artículo hemos repasado algunas de ellas, quizá las más fundamentales. ${ }^{26}$ También hemos visto cómo la mayoría de ellas van encaminadas a posibilitar que el ser humano pueda abrirse cognoscitivamente a la realidad, entre la que incluimos a uno mismo. Sucede empero que, a pesar de la reconocida importancia adaptativa de tal labor, no conseguimos otorgar a la atención ningún protagonismo estructural en el engranaje humano, al contrario, su desempeño se produce siempre a la sombra de otros fenómenos más reconocibles como pueden ser la memoria, la percepción, la motivación, la toma de conciencia o la ejecución de tareas, por citar algunos ejemplos. La atención - ese «raro» fenómeno- desempeña, en el existir humano, un rol que bien podría memorar al de un mayordomo en un complejo y dinámico palacio orgánico, pues lo que sabemos cierto de ella es que su tarea consiste en un compromiso auxiliar y asistente para que las demás funciones cognitivas y emocionales puedan desarrollarse debidamente, procurando por el adecuado funcionamiento del palacio humano en su coexistencia con el resto de elementos del entorno.

21 Sobre los problemas a la hora de definir qué es la atención y qué funciones se le pueden asignar, ver: STYLES, E. A. (2010). La psicología de la atención. Madrid: Ed. Ramón Areces.

22 JAMES, W. (1989). Principios de Psicología. vol. 1. México: FCE, p. 403.

23 AGUSTÍN. (1986). Confesiones. Bogotá: Editorial San Pablo, p. 489.

24 HUSSERL, E. (2015). Investigaciones lógicas 1. Madrid: Alianza, p. 338.

25 En CRARY, J. (2008). Suspensiones de la percepción. Atención, espectáculo y cultura moderna. Madrid: Akal. p. 67.

26 Ver nota 11. 
No es extraño, pues, que lleguemos a creer que quizá su merecimiento sea a la vez la respuesta a la dificultad de su aprehensión.

Cuando hablamos del palacio humano y del papel de mayordomo en la atención, nos estamos situando en el terreno metafórico, pero clarividente, de abordar la intimidad humana a través de una tópica o geografía íntima como hiciesen algunos modelos psicoanalíticos en su tiempo, podemos citar las tópicas freudiana o junguiana. Existen otras, obviamente. A nosotros nos gusta aludir a una mucho más cercana e igualmente perspicaz, la visión tópica orteguiana. Nos gusta e interesa porque en ella, el papel de la atención como asistente o mayordomo se aprecia con suma claridad, que es lo que al fin y al cabo nos interesa ilustrar.

Ortega esbozó su tópica interior en un texto de 1925 publicado bajo el nombre de «Vitalidad, alma, espíritu». El texto fue la expresión de unas conferencias sobre antropología filosófica en las que desgranó la integridad de las intimidades del ser humano mediante una tectónica muy al estilo psicodinámico. ${ }^{27}$ No es motivo del presente artículo analizar los pormenores de dicha tópica, para ello existe ya mucha bibliografía, ${ }^{28}$ pero sí esbozaremos una sucinta aproximación para desvelar en ella el papel de la atención en su puesta en marcha, en su funcionamiento habitual.

Ortega distribuye su tópica en tres regiones fundamentales, una de ellas es el alma corporal o vitalidad. Esta esfera supone el cimiento donde se funden lo somático y lo psíquico en el sujeto ${ }^{29}$ la región de la que emerge la fuerza vital, un poso de energía que nutre el resto de nuestra persona y que establece nuestro carácter. Es una región «subconsciente, oscura y latente, que se extiende al fondo de nuestra persona como un paisaje al fondo del cuadro». ${ }^{30}$ Como bien indica Serrano de Haro, la vitalidad se «identifica con el cuerpo vivido

27 En esta pretensión de realizar una distribución, ternaria, de la intimidad humana, no podemos dejar de ver bastantes paralelismos -pese a las críticas explícitas en el texto hacia el psicoanálisis- entre la distribución orteguiana y la tópica freudiana. Como ejemplo del paralelismo tenemos las notorias semblanzas entre los conceptos de vitalidad y pulsión; alma y deseo inconsciente; o de espíritu y yo consciente. En GARCÍA LARA, J. E. (2002). Ortega y Gasset y el psicoanálisis. Universidad Complutense de Madrid. [En línea]: http://eprints.ucm.es/4118/.

28 Sobre «Vitalidad, alma, espíritu» ver los textos críticos de SERRANO DE HARO, A. (2013). Apariciones y eclipses del cuerpo propio. En ZAMORA BONILLA, J. (Ed.). Guía Comares de Ortega y Gasset. Granada: Ed. Comares, pp. 311-327 y (2010). Atención y dolor. Cuerpo Vivido. Madrid: Ed. Encuentro,pp. 123-161; o el citado de GARCÍA LARA, J. E. op. cit..

29 Freud define el concepto «pulsión» en semejantes términos a los que Ortega usa para «vitalidad». Dice el austriaco de la pulsión que es «un concepto límite entre lo anímico y lo somático, $[. .$.$] como una magnitud de la exigencia de trabajo impuesta a lo anímico a consecuencia$ de su conexión a lo somático» (Freud O.C.T.II, pp. 2040-2041).

30 OC, II, 576. Vitalidad, alma, espíritu. 
por dentro [...], cuerpo que el yo hace suyo y que sostiene a la persona». ${ }^{31}$ Es el cuerpo consciente sobre el que se erige, en la cima de su fondo, coronando el ancho campo pulsional, «lo más personal de la persona»: ${ }^{32}$ el espíritu, esto es, el «conjunto de los actos íntimos de que cada cual se siente verdadero autor y protagonista [...] lo que estrictamente debe llamarse 'yo'». ${ }^{33}$ De el espíritu nos dice García Lara que:

es el mundo de lo cultural, [...] lo psicológico, las facultades de nuestra conciencia, que nos permiten reconocernos como nosotros mismos, autores de nuestros actos, directores y administradores de nuestros recursos mentales, planificadores de nuestros proyectos vitales y orientados en un tiempo y un espacio en los que reconocemos las referencias que nos sirven de balizamiento en nuestro caminar existencial. ${ }^{34}$

Y entre la vitalidad y el espíritu, en un terreno intermedio, como la atmosfera que rellena el espacio intersticial, aparece «la región de los sentimientos y emociones, de los deseos, de los impulsos y apetitos, lo que vamos a llamar, en sentido estricto, alma». ${ }^{35}$

El alma será la región que más nos comprometa, pues el alma contiene, disipados en los poros de su ambiente, los impulsos, las preferencias y apetitos de la persona, aquellas emergencias que espolean al foco de nuestra atención y que estimulan el resto de nuestro ser a tender hacia algo, hacia aquello que le cautive. Unas emergencias, por ello, que el espíritu se encargará afanosamente de desatar o reprimir cual Yo freudiano, pues, al fin y al cabo, «Yo soy el que piensa, el que decide y quiere». ${ }^{36}$ Como diría el mismo Freud:

El pobre yo [...] sirve a tres severos amos y se esfuerza en conciliar sus exigencias $\mathrm{y}$ sus mandatos. Tales exigencias difieren siempre, $\mathrm{y}$ a veces parecen inconciliables [...].Sus tres amos son el mundo exterior, el super-yo y el ello [...] conducido por el ello, restringido por el super-yo y rechazado por la realidad, el yo lucha por llevar a cabo su misión económica, la de establecer una armonía entre las fuerzas y los influjos que actúan en él y sobre él. ${ }^{37}$

Así, el espíritu -metiéndonos ya en plena dinámica interna donde la atención reviste un protagonismo reconocible- se erige como el apoderado -que nunca

31 SERRANO DE HARO, A. op. cit., p. 315.

32 OC, II, 575.

33 Ibíd.

34 GARCÍA LARA, J. E. op. cit., p. 284.

35 OC, II, 576.

36 Ibíd.

37 Freud O.C.T. III, pp. 3144-3145. 
propietario- para instaurar el orden en el palacio de nuestra persona, de nuestra vida íntima, ejerciendo arbitraje sobre las demandas del alma cual salón repleto de invitados en un convite de gourmets. Podríamos decir que cada huésped de esta mansión, cada invitado, con derecho autoadquirido, desata sus apetencias y exige su satisfacción, despliega sus amores, sus odios, sus deseos. El alma, convertida en ese salón de banquetes, se ve inundada por las exigencias de los invitados, colmada de pulsiones. Frente a ellas -siguiendo nuestra práctica analogía- aparece, como siempre sumido en pleno meollo, nuestro mayordomo (la atención). Si, como requiere el alma, la atención tuviese que responder a todas las demandas de sus invitados, a todas las pulsiones, colapsaría y la mansión quedaría desatendida, indefensa, tal que pronto enfermaría por el desorden y la locura. Para evitar tal aluvión, se despliega el espíritu que, «como jefe de policía, sentencia sobre ellos como un juez, los disciplina como capitán». ${ }^{38}$ El espíritu, ejerciendo de agente mediador, pugna con los arrebatos del alma para interceder en la autorización o restricción de qué atenciones ofrecer a los invitados. El Yo, tratando de mostrarse solemne e imperioso, en su pugna con el alma, intenta imponer, consiguiendo siempre modular, las gestiones que la atención dispensará para con ciertos apetitos, silenciando otros. La atención pues -nuestro mayordomo-, destinada a satisfacer las necesidades de los inquilinos, espoleada por las demandas que del alma emerjan, actuará -en su mayor parte y bajo un prisma de salubridad-organizada y bajo aprobación del espíritu y su influjo moderador.

El espíritu o «yo» no puede, por ejemplo, crear un sentimiento, ni directamente aniquilarlo. En cambio, puede, una vez que ha surgido un deseo o una emoción en cierto punto del alma, cerrar el resto de ella e impedir que se derrame hasta ocupar todo su volumen. ${ }^{39}$

Así, el espíritu, en última instancia, indicará a la atención el grado de tolerancia o apertura que deba dejar al alma, la premura y eficiencia en la satisfacción de sus demandas para una mejor adaptación al entorno. De ahí que digamos que la atención responde siempre a un interés y no a pulsiones o apetitos anímicos, pues la atención siempre actuará según sea el resultado de la ancestral y constante pugna entre el alma y el espíritu. Ese es el mecanismo por el cual el sujeto acaba, como explicábamos anteriormente, reparando en determinados elementos del entorno y, en cambio, se mantenga desinteresado hacia los demás, siga únicamente contando con ellos, sin ofrecerles un especial acento. El alma exige a nuestro espíritu la satisfacción de ciertas demandas y este, pese a la responsabilidad que ostenta en el mantenimiento del orden y la cordura y su

38 OC, II, 577.

39 Ibíd. 
capacidad de restricción, debe, como poco, elegir siempre de entre las opciones que el alma le presenta, esto es, conformarse con ser gestor o dispensador de concesiones, de desatar la atención frente a uno u otro interés, pero siempre tras ese interés. Dicho de otro modo, el espíritu nunca propone - «no puede crear un sentimiento»-, solo dispone, pues quien propone es el alma. No existe otro modo que se pueda considerar saludable. «Cabe, pues, bajo el imperio de la voluntad [espiritual] contraer el alma [...] o, por el contrario, esponjarla, dilatar sus poros». ${ }^{40}$ Según sea el régimen de tolerancia que se instaure frente a cada situación o contexto, la atención reparará en unos u otros estímulos, según los preceptos del interés, según las excitaciones y restricciones que un determinada situación despierte en el interior del palacio humano.

En virtud de ello, de si nuestra alma se halla -por consentimiento espiritual- más cerrada o abierta, porosa o hermética, provocaremos según Ortega dos estados en la persona: el sensible o el sentimental. Esto es, en función de si el alma se halla abierta o cerrada hacia fuera o abierta o cerrada hacia adentro tendremos un estado de mayor o menor alteración o, por el contrario, de pleno ensimismamiento. Hasta tal punto puede la atención revelar el carácter de la persona.

Huelga decir que la atención se erige, en esta distribución, como elemento necesario para comprender el funcionamiento del expuesto sistema humano. Quizá, estructuralmente no forme parte de la tríada tópica, ni ocupe de arranque un lugar prioritario. Pero en el momento en que todo explorador de las intimidades desea mostrar una tópica con carácter dinámico, funcional, debe enfrentarse a elementos activos y, entre ellos, la atención destaca por derecho propio: por su potencial dinámico e integrador; por su capacidad de ejercer como argamasa articulatoria en el mantenimiento integral de un palacio que, en su vital funcionamiento, debe actuar como un engranado sistema de relaciones pues, de otro modo, fenecería por desadaptación; por su capacidad de ser, en reacción al interés desatado en la pugna alma-espíritu, el elemento administrador, en última instancia, de la apertura del palacio a aquellos estímulos que le comprometen. La atención, en resumidas cuentas, no es estructuralmente nada en el palacio humano, sin embargo lo es todo a nivel funcional.

\section{CONCLUSIÓN}

Así, con lo repasado hasta el momento, creemos que ha quedado patente cómo la atención es el fenómeno cognitivo -con importantes porosidades a aspectos culturales y emocionales de la persona- responsable de que el ser humano alcance a tomar consciencia de su mundo en torno, se abra cognoscitivamente a la realidad. Y, precisamente, por sus distintas permeabilidades, 
por su disposición a ser movida no solo por los impulsos biológicos del alma, sino por las disposiciones del espíritu, esto es, por intereses, es la atención un fenómeno que individualiza la relación del sujeto humano con su entorno. Nuestra experiencia previa, nuestros anhelos, todo nuestro proyecto de vida se entremezcla con las apetencias fisiológicas de nuestro organismo a la hora de disparar la flecha atencional, haciendo que su lanzamiento sea particular en cada caso, una personal e intransferible perspectiva, pues, en palabras de Ortega, «cada hombre tiene una misión de verdad. Donde está mi pupila no está otra: lo que de la realidad ve mi pupila no lo ve otra». ${ }^{41}$

Esto nos debería llevar a plantear cierta reflexión sobre la forma de abordar el modo en que el ser humano se abre a su circunstancia, esto es, el modo en que el ser humano existe y, en consecuencia, es. Como ya advirtiese Binswanger en su revisión de la Daseinanalytik heideggeriana, ${ }^{42}$ el abordaje de lo que el ser humano es no debiera nunca renunciar a poder ir «más acá» de una aproximación ontológica, e intentar alojarse en un espacio de comprensión más antropológico, buscando alcanzar daciones del ser mucho más concretas y descriptibles, más pragmáticas, esto es, los modos particulares de existencia en y por sí mismos. Si nuestro abordaje es meramente ontológico, la aproximación individual, la que atiende a cada historia de vida, a cada perspectiva y, en consecuencia, a cada pueblo, comunidad y sujeto -entendiendo por sujeto un ser «de carne y huesos»-, se ve comprometida.

En semejante contexto, el estudio de la atención nos ofrece, ni más ni menos, que uno de los «escotillones y rendijas por donde deslizarse a lo profundo de la persona». ${ }^{43} \mathrm{La}$ atención es una respuesta directa y franca a nuestros intereses, a nuestra sensibilidad; la dirección que toma la atención en cada caso responde al conjunto de motivaciones que se forjan y subyacen en nuestro interior, un disparo que «al llegar al haz visible de la vida arrastra en aluvión algas y conchas del abismo interior». ${ }^{44}$ Por ello, a través de un minucioso estudio de lo que cada cual atienda en cada momento podemos llegar a advertir los retazos íntimos que lo impelen, esa individualidad que nos permite abordar a cada sujeto descriptivamente, en sí mismo. Esos restos que la atención arrastra nos permiten alcanzar, cual arqueólogos del alma, el fondo insobornable ${ }^{45}$ de cada cual. De

41 OC, II, 163. Verdad y perspectiva.

42 Ver BINSWANGER, L. (1942). Grundformen und Erkenntnis menschlichen Daseins. Zürich: Max Niehans; (1955). Das Raumproblem in der Psychopathologie. Ausgewählte Vorträge und Aufsätze. Band II. Bern: Francke Verlag.

43 ORTEGA Y GASSET, J. (2006). Estudios sobre el amor. Obras Completas, V. Madrid: Taurus, p. 502.

44 Ibíd., p. 500.

45 El fondo insobornable es un concepto tan importante como frecuente en el pensamiento orteguiano. Aparece por vez primera en «Vieja y nueva política», en 1914 y se repetirá 
ahí que Ortega afirmase sin ambages -y nosotros con él- aquello de «dime lo que atiendes y te diré quién eres». ${ }^{46}$

\section{REFERENCIAS BIBLIOGRÁFICAS}

AGUSTÍN. (1986). Confesiones. Bogotá: Editorial San Pablo.

BINSWANGER, L. (1942). Grundformen und Erkenntnis menschlichen Daseins. Zürich: Max Niehans,

_-_, (1955). Das Raumproblem in der Psychopathologie. Ausgewählte Vorträge und Aufsätze. Band II. Bern: Francke Verlag.

CRARY, J. (2008). Suspensiones de la percepción. Atención, espectáculo y cultura moderna. Madrid: Akal.

FREUD, S. (1972). Obras completas. Madrid: Biblioteca Nueva.

GARCÍA LARA, J. E. (2002). Ortega y Gasset y el psicoanálisis. Universidad Complutense de Madrid. [En línea]: http://eprints.ucm.es/4118/

HABERMAS, J. (1982). Conocimiento e interés. Madrid: Taurus.

HEIDEGGER, M. (2009). Ser y tiempo. Madrid: Ed. Trotta.

HUSSERL, E. (2015). Investigaciones lógicas 1. Madrid: Alianza.

JAMES, W. (1989). Principios de Psicología. vol. 1. México: FCE.

LASAGA, J. (2006). Figuras de la vida buena. Ensayo sobre las ideas morales de Ortega y Gasset. Madrid: Enigma, Fundación José Ortega y Gasset.

LUCK E. J. y VECERA, S. P. (2002). Attention. Stevens' Handbook of Experimental Psychology, vol. 1. Sensation and Perception. PASHLER, H. y YANTIS, S. (eds.). Nueva York: John Wiley \& Sons, Inc., pp. 235-286.

MERLEAU-PONTY, M. (1985). Fenomenología de la percepción. Barcelona: Planeta.

a lo largo de su obra siendo uno de los conceptos fundamentales en su antropología filosófica y moral, pues ese fondo es el que nos interpela para decirnos lo que realmente somos. San Martín (2007) realiza un registro exhaustivo de sus apariciones, así como un comentario a su valor en la filosofía del madrileño. También es interesante leer el análisis que realiza José Lasaga en (2006) Figuras de la vida buena. Ensayo sobre las ideas morales de Ortega y Gasset. Madrid: Enigma: Fundación José Ortega y Gasset.

46 ORTEGA Y GASSET, J. (2006). Estudios sobre el amor. Obras Completas, V. Madrid: Taurus, p. 479. 
MONTESÓ, J. (2016). Ortega y los predicados culturales de la percepción. Ágora: papeles de filosofía, 35 (2), pp. 157-175.

MORÓN ARROYO, C. (1968). El sistema de Ortega y Gasset. Madrid: Alcalá.

ORTEGA Y GASSET, J. (2004). Meditaciones del Quijote. Obras Completas, I. Madrid: Taurus.

- - - (2004). Verdad y perspectiva. Obras Completas, II. Madrid: Taurus.

_- - (2004). Vitalidad, alma, espíritu. Obras Completas, II. Madrid: Taurus.

_- - (2005). La deshumanización del arte e ideas sobre la novela. Obras Completas, III. Madrid: Taurus.

- - , (2006). Estudios sobre el amor. Obras Completas, V. Madrid: Taurus.

- - , (2006). Corazón y cabeza. Obras Completas, VI. Madrid: Taurus.

_-_, (2008). Principios de metafísica según la razón vital. Curso de 1932-1933. Obras Completas, VIII. Madrid: Taurus.

RODRÍGUEZ HUÉSCAR, A. (1985). Perspectiva y verdad. Madrid: Alianza.

SAN MARTÍN, J. (2007). Vocación y profesión: Bases orteguianas para una ética del futuro. En CEREZO GALÁN, P. (Ed.). Ortega en perspectiva. Madrid: Instituto de España, pp. 89-112

- - - (2008). La percepción como interpretación. Investigaciones fenomenológicas, 6, pp. 13-32.

- - , (2012). La fenomenología de Ortega y Gasset, Madrid: Biblioteca Nueva.

SCHAPP, W. (1910) Beiträge zur Phänomenologie der Wahrnehmung. Gotinga: M. Niemeyer, Halle/S.

SCHELER, M. F. (1926). Die Wissensformen und die Gesellschaft. Leipzig: Der Neue Geist Verlag.

- - , (2001). Ética: nuevo ensayo de fundamentación de un personalismo ético. Madrid: Caparrós.

SERRANO DE HARO, A. (2013). Apariciones y eclipses del cuerpo propio. En ZAMORA BONILLA, J. (Ed.). Guía Comares de Ortega y Gasset. Granada: Ed. Comares, pp. 311-327.

- - - (2010). Atención y dolor. Cuerpo Vivido. Madrid: Ed. Encuentro, pp. 123-161.

STYLES, E. A. (2010). La psicología de la atención. Madrid: Ed. Ramón Areces.

VYGOTSKI, L. S. y LURIA, A. R. (2007) El instrumento y el signo en el desarrollo del niño. Madrid: Fundación Infancia y aprendizaje. 
Jorge Montesó Ventura es doctor en Filosofía y licenciado en psicología y antropología, es miembro fundador del Centre d'estudis antropològics ACAF donde, actualmente, dirige la sección de antropología Filosófica.

Líneas de Investigación:

Antropología filosófica, teoría del conocimiento y fenomenología.

Publicaciones recientes:

-(2016). La atención en el pensamiento de Ortega y Gasset. Castelló: Centre d'Estudis Antropològics ACAF

-(2017). «El análisis existencial de Binswanger y la antropología orteguiana, puntos de encuentro». Éndoxa. Series filosóficas, 39, 285-303.

-(2016). «La teoría histórico-cultural de Vygotski desde una perspectiva fenomenológica», Investigaciones fenomenológicas, 13, 107-126.

-(2016). «Ortega y los predicados culturales de la percepción».Ágora: papeles de filosofía, 35 (2), 157-175.

-(2015). «Las fuentes orteguianas en su idea de 'atención'». Investigaciones fenomenológicas, 12, 137-156.

Correo electrónico: jmonteso.acaf@gmail.com 